\title{
ANALYSIS OF CRYPTOCURRENCIES MARKET: CURRENT SITUATION, TENDENCIES OF HOUSEHOLD INVESTMENT AND FUTURE FORECASTING
}

\author{
Ina PIECZULIS*, Kamilè TAUJANSKAITĖ \\ Department of Financial Engineering, Faculty of Business Management, \\ Vilnius Gediminas Technical University, Sauletekio al. 11, 10223, Vilnius, Lithuania \\ *E-mail: ina.pieczulis@stud.vgtu.lt
}

\begin{abstract}
Purpose - the purpose of this study is to analyse the cryptocurrency market and to forecast household investments in it from a theoretical and practical point of view.

Research methodology - in order to achieve the aim of the article, scientific literature and statistical data analysis, comparative analysis and SWOT analysis were done. Also, ARIMA forecasting model was adapted to forecast Household investment in cryptocurrencies.

Findings - the first part of the study presents the theoretical aspects of cryptocurrencies. An overview of the cryptocurrencies and their market is provided, focusing on the concept of Bitcoins, its' mining and technical principles of operation. The second part of this study is intended to analyse the cryptocurrencies market and its dynamics. In the last part of the research tendencies of household investments in cryptocurrencies are examined for the period of 2016-2019 according to the data from cryptocurrency exchange. Also, household investments in cryptocurrencies are analysed and major future investment trends and seasonality are identified as well. Household future investment in cryptocurrencies is also predicted.
\end{abstract}

Research limitations - data used in the research only includes currency exchange information, that may be inaccurate when concluding the main trends of the market.

Practical implications - the practical results of the study may be useful for households interested in investing, especially in risky investment alternatives. Results of the research justify the dynamics of the currency market and the fluctuation of cryptocurrencies' prices that shows that investment in cryptocurrencies is very variable, unstable and risky.

Originality/Value - cryptocurrencies market is particularly dynamic and fast-changing, so the newest scientific investigations are urgent. In this research, an attempt was made to forecast household investment in main cryptocurrencies.

Keywords: cryptocurrency, cryptocurrency market, investments in cryptocurrencies, Bitcoin, Ethereum, DASH, NEM.

JEL Classification: C12, D53, F31, 031.

Conference topic: Contemporary Financial Management.

\section{Introduction}

The world of money and finance is transforming before our eyes. Digitised assets and innovative financial channels, instruments and systems are creating new paradigms for a financial transaction and forging alternative conduits of capital (Hileman \& Rauch, 2017). As contemporary financial markets expand and evolve, another, very fast-growing investment opportunity - cryptocurrencies - have emerged. At present, the cryptocurrency market is probably the fastest growing and most developing market (Caporale \& Zekokh, 2019). This currency market is extremely dynamic and risky. Changes in cryptocurrency market are hard to predict and very fast, so even professional cryptocurrency investors need to keep track of price changes and keep their hands on the crypto market's pulse in order not to miss any significant change that may affect investment decisions and their success.

The topic of cryptocurrencies and related aspects during the last decade has recently become very popular not only for investors but for scientists as well. Chaum, Fiat, and Naor (1990) analysed electronic cash, Camenisch, Hohenberger, and Lysyanskaya (2005), Kosba, Miller, Papamanthou, Shi, and Wen (2015) analysed application of cryptography, Bonneau et al. (2015), Narayanan, Bonneau, Felten, and Miller (2016) investigated perspectives and challenges of cryptocurrencies and related technologies, Phillip, Chan, and Peiris (2018) analysed a new look in cryptocurrencies and related challenges, Hileman and Rauchs (2017) analysed exchanges, wallets, payments and mining of 
cryptocurrencies, Hayes (2016) analysed aspects of cryptocurrency value formation, Fry and Cheah $(2015,2016)$ analysed negative bubbles and shocks in cryptocurrency market, Halaburda and Gandal (2014) analysed competition in the cryptocurrency market. Bitcoins were analysed by Nakamoto (2008), Barber, Boyen, Shi, and Uzun, (2012), Yermack (2013), Bentov and Kumaresan (2014), Dwyer (2015), Ruffing, Kate, and Schröder (2015), Sompolinsky and Zohar (2013), Katsiampa (2017). Also, security aspects of financial operations with cryptocurrencies are analysed as well by scientists, such as Schoenmakers (1998), Rosenberg (2010), Andrychowicz, Dziembowski, Malinowski, and Mazurek (2013).

The popularity of cryptocurrencies is determined by many features, but the most popular ones are easy to access, high liquidity and high profitability (Wang, Shen, Li, Shao, \& Yang, 2019). It is an illusion in a society that cryptocurrencies are an easy, profitable and safe investment (Fry \& Cheah, 2016; Corbet, Larkin, Lucey, \& Yarovaya, 2018; Hafner, 2018). However, often such thinking goes beyond reality.

Another factor that determines the popularity of cryptocurrencies, according to Eom, Kaizoji, Kang, and Pichl (2019), is the high volatility. No one knows what the future holds for cryptocurrencies, although Dibrova (2016) sees great potential for the development of the cryptocurrency market. It is very important to monitor this market and its anomalies and significant changes as closely as possible. This would help prevent possible ignorance and facilitate decision-making in critical situations, especially since the cryptocurrency market is not yet fully known and discovered (Caporale, Gil-Alana, \& Plastun, 2018).

The attractiveness, high volatility and uncertainty of the cryptocurrency market mean that the newest related research is very relevant. The vast majority of the research carried out before analyzed past data and in this paper, an attempt was made to analyse and forecast household future investments in cryptocurrencies till 2020 according to the data from currency exchange.

Thus, the object of this research is the cryptocurrencies market. The purpose of this article is to analyse contemporary issues of cryptocurrencies market and the volume of household investment in it according to the data of cryptocurrency exchange $\mathrm{X}$.

To achieve this goal, the analysis and systematization of academic literature, reviews of related research, analysis of the latest statistical data, graphical modelling of households' investment in cryptocurrency and forecasting of statistical data using the ARIMA forecasting model are performed.

\section{Conceptual aspects of household investment in cryptocurrencies}

The $21^{\text {st }}$ century is described as the age of growth in technology and the popularity of Internet use, which has led to the creation of a monetary system through the introduction of a new phenomenon - virtual currencies, which a decade ago led to the creation of another form of settlement - the cryptocurrency. It is neither a product nor fiat money - it is a new, experimental type of money and attempts are being made to explore the aspects of its use that have not yet been discovered. Because of the recent interest in cryptocurrencies as an investment tool, the need for a detailed analysis of this market, the prices of the most popular cryptocurrencies, and, most importantly, predicting the fluctuations of its prices and the volume of investment in this market are needed (Antonakakis, Chatziantoniou, \& Gabauer, 2019). Many scientists argue that the golden age of cryptocurrency market is already in the past (Roubini, 2018), while others argue that this market still has a lot of untapped potentials (How the cryptocurrency market..., 2018).

\subsection{Analysis of conceptual aspects of cryptocurrencies}

According to Andrantas and Diputra (2018), cryptocurrency is a virtual currency belonging to a highly expanding payment system. Dourado and Brito (2014) say that cryptocurrency is a system name that uses cryptography to securely transmit and exchange digital tokens in a redistributed and decentralized system. It is a completely anonymous payment instrument that eventually became an investment object.

According to Caporale et al. (2018), the cryptocurrency market is still young as it was created in 2009, but became popular only in 2013, although it has not yet been fully explored. Cryptocurrencies attracted the attention of many people: from individuals interested in blockchain technology and payment processing activities to invest in them, to retailers, large corporate investors, investment fund managers, securities regulators, banking and accounting professionals, and even governments. It is virtual currency that has no connection with jurisdiction and legal regulation that exists in a public, computer-supported, network of people (Platanakis \& Urquhart, 2019).

There are noticeable differences between fiat currencies and cryptocurrencies. The nature of the cryptocurrencies is completely different from the dollar, euro or other. The main differences between these currencies, according to Andrianto and Diputra (2017), are that fiat currencies are entirely dependent on the state, global economic conditions such as inflation, trade, crisis, policy. In addition, fiat currencies can be counted more accurately than cryptocurrencies. However, the changes in cryptocurrency prices are larger, more complex and difficult to predict. Although $\mathrm{Yi}, \mathrm{Xu}$, and Wang (2018) consider the most interesting difference between crypto and traditional currencies is the fact that the first one creates a completely new payment system based on cryptographic protocols that can provide anonymity, low cost, and fast transaction execution. 
Platanakis and Urquhart (2019) argue that cryptocurrencies are not just payment systems and tools. Nowadays, it is a very popular investment tool that allows investors to earn income from sudden and hard-to-predict changes in cryptocurrency prices. This is a particularly risky market because the changes in the value of the cryptocurrency take place almost every minute, are sudden, hard to predict and very significant (Chaim \& Laurini, 2018). Caporale and Zekokh (2019) say that two large exchanges, i. e. Chicago Mercantile Exchange and Chicago Board Options Exchange have begun to trade bitcoins as future trades. Investing in cryptocurrencies, according to Kajtazi and Moro (2018), and Platanakis and Urquhart (2018), can be included in the investment portfolio, which has proved to be very useful, thanks to research by the aforementioned scientists. Investing in cryptocurrencies is becoming simpler and more popular over time, with more and more opportunities for it, and for example, Dibrova (2016) notices that the cryptocurrency market has great potential for future development.

\subsection{Most popular cryptocurrencies}

Wang et al. (2019) write that in 2017, the market value of cryptocurrencies increased more than 30 times: from about USD 17 billion from January 1 to USD 591 billion. CoinMarketCap.com updates the data on the cryptocurrencies every day and publishes a list of the most popular cryptocurrencies from 15,825 exchanges, with their 24-hour transactions in cash and prices.

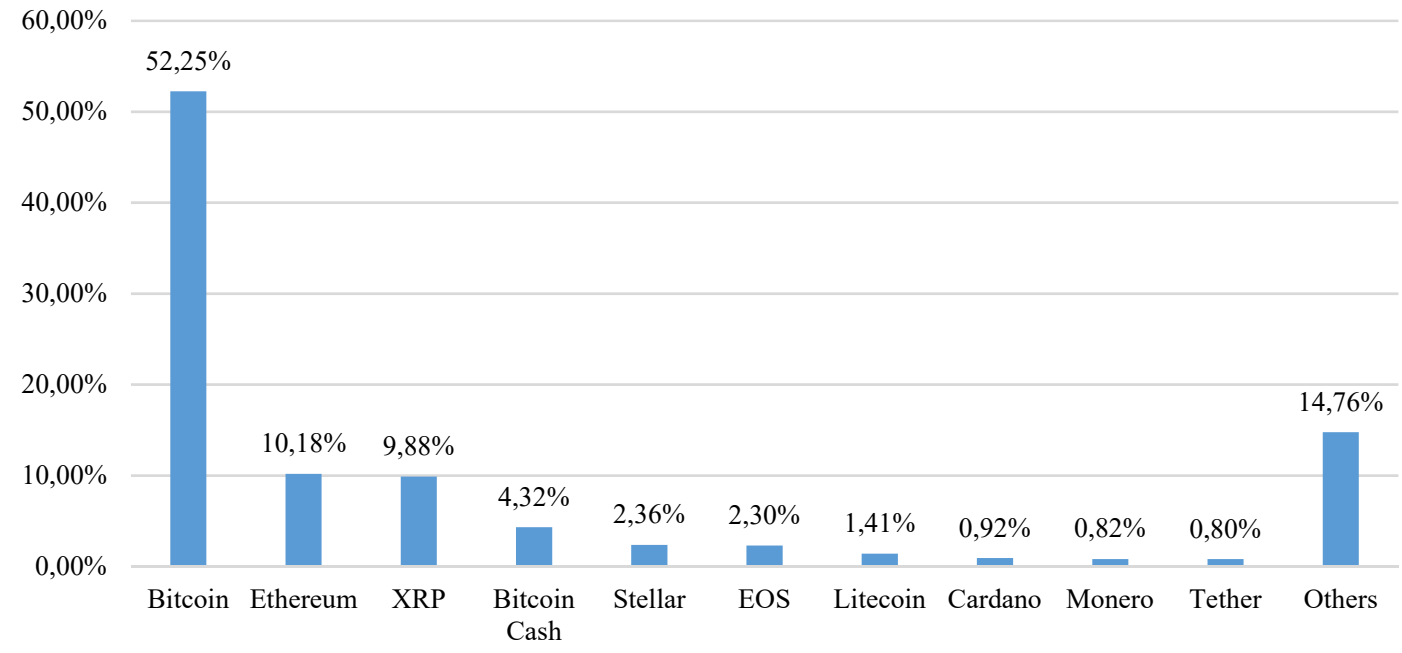

Figure 1. Structure of cryptocurrencies market according to the monetary volume of last 24 hours transactions on 13 November 2018 (composed by authors, according to the data provided by (CoinMarketCap.com, 2018)

Figure 1 shows that the 10 most popular cryptocurrencies are: Bitcoin, Ethereum, XRP, Bitcoin Cash, Stellar, EOS, Litecoin, Cardano, Monero and Tether. Unmatched first-rate leaders in this hierarchy are BTCs, with a market capitalization of up to $52.25 \%$ of total market capitalization. This means that more than half of the money invested in cryptocurrencies is invested in bitcoins. In the near future, probably not one cryptocurrency will be able to pose a serious threat to the market position of bitcoin, since Ethereum, ranked second, represents only $10.18 \%$ of the total market capitalization. With a slight difference compared to Ethereum is behind XRP $(9.88 \%$ of total market capitalization). Bitcoin Cash, ranked fourth, accounts for $4.32 \%$ of total market capitalization, which is two times less than Ethereum and XRP. Stellar and EOS account for $2.36 \%$ and $2.30 \%$ respectively of total market capitalization and Litecoin for $1.41 \%$. All other cryptocurrencies listed below represent less than $1 \%$ of total market capitalization. For the remaining 2084 cryptocurrencies, only $14.76 \%$ of the total market capitalization is left, which on average each yield only $0.007 \%$ of the total market capitalization.

Andrianto and Diputra (2017) say bitcoin has become the most widely used cryptocurrency, as evidenced by the market capitalization of bitcoins, which is as high as USD 95,405,929,252 (CoinMarketCap.com, watched on 13 November 2018). Cryptocurrency initiator Satoshi Nakamoto (2008) created the very first cryptocurrency - bitcoin. Although no one knows the real name of the creator (there is speculation that Satoshi Nakamoto is the nickname of a Japanese developer or group of developers), the results of his work are well known to everyone. According to Geiregat (2018), the cryptocurrency system is the implementation of the theoretical model of Satoshi Nakamoto. The main idea of the theoretical model is to create a digital transaction system, which would be decentralized, which means that governments, financial institutions and other third parties would not participate in the system and would not influence transactions within the system (Nakamoto, 2008). Geiregat (2018) is convinced that such systems inevitably require participants to rely on these third parties and, as a result, they are fundamentally flawed. Borri (2019) is convinced that cryptocurrency admirers strongly believe in the power of computers and the high level of transparency that allows everyone to follow the actions of other users. People from all over the world collectively implemented this model and 
created the system Bitcoin. Later, other cryptocurrency systems appeared too. However, all subsequent cryptocurrency systems are based on the Bitcoin system. In order for the systems to function properly, they need to have trading units, the so-called coins.

The very first cryptocurrency system proposed by Satoshi Nakamoto is bitcoin. Kądziołka (2015) defines bitcoin as a virtual currency operating on the P2P (peer-to-peer) network that directly connects the two sides without the assistance of financial institutions. Bitcoins provide the opportunity to pay for goods or services. Chan, Chu, Nadarajah, and Osterrieder (2017) report that bitcoins, the first decentralized cryptocurrency, have gained such high popularity due to cryptographic proof.

More and more attention is now being paid to the behaviour of cryptocurrencies (Yi et al., 2018). Scientists are trying to find out the connection between macroeconomic factors and bitcoins. Corbet, Lucey, and Yarovaya (2017) analyzed the link between macroeconomic news and revenue from bitcoin, and found that news related to unemployment and long-term consumer goods has a significant impact on revenue from bitcoins, and news on gross domestic product and consumer price index seems to have no statistically significant impact on the Bitcoin system.

\section{Overview of cryptocurrency market trends}

As mentioned earlier, in 2009 there was a huge explosion in the currency market because then the first cryptocurrency was introduced - bitcoin. This phenomenon has led to a number of discussions between famous world economists, financial specialists and scientists. The running time has proven that the public lacks a global currency based on completely different rules than existing fiat currencies.

\subsection{General overview and SWOT analysis of cryptocurrencies market}

Yi et al. (2018) write that the cryptocurrency market is the most volatile market. Many scientists are currently studying the cryptocurrency market, their price relationship with microeconomic and macroeconomic factors, and are trying to identify the factors that influence the changes in cryptocurrency prices. Ciaian, Rajcaniova, and Kancs (2016) have identified three key factors that influence the cost of cryptocurrency transactions:

- An interaction between demand and supply.

- Attractiveness for investors and technological change.

- Macroeconomic conditions and financial developments.

Glaser, Zimmermann, Haferkorn, and Siering (2014) believe that the media and the news they provide also have a strong impact on cryptocurrency price fluctuations. Due to the large and unpredictable changes in cryptocurrency prices, it is very difficult to get a strong and appropriate position in trading and investing in this market to get the most benefit and profit. Investments in cryptocurrency are risky because of the high risks involved, including currency fluctuations, operational and security risks (Ciaian et al., 2016).

For a better understanding of the cryptocurrency system and the market, a SWOT analysis was performed. SWOT is a method that allows to identify the strengths and weaknesses of an object and to identify opportunities and threats that arise from the environment (Phadermrod, Crowder, \& Wills, 2019). Fast (1) and cheap (2) transactions belong to the strong sides of the cryptocurrency system and the market (see Table 1). This is a great advantage because international orders made by banks or similar entities take a very long time and cost a lot of money, so these qualities are very important and, to a large extent, have led to the popularity of the cryptocurrencies. The absence of intermediaries (3) is also one of the highly appreciated strengths. This feature saves you time and money in transactions worldwide. Selfregulatory processes (4) are taking place in the marketplace, meaning that, in practice, no country or organization has the potential to increase the supply of cryptocurrencies. The last strength is the anonymity (5) of the data of the system participants. This means that each participant in the system works on the principle of their own public key. The system does not transfer personal data to keys. However, it should be noted that all transactions in the system are publicly available. A person who can link an address to a user's personal data can find out the current status of their account and transaction history.

Table 1. Cryptocurrency systems and market SWOT analysis: strengths and weaknesses (composed by the authors)

\begin{tabular}{|l|ll|}
\hline \multicolumn{1}{|c|}{ Strengths (S): } & \multicolumn{1}{c|}{ Weaknesses (W): } \\
\hline 1) Quick transactions; & 1) & A non-material form; \\
2) Cheap transactions; & 2) & The high volatility of the currencies' course; \\
3) No intermediaries; & 3) & Lack of protection against user error; \\
4) Market self-regulation processes; & 4) & Value of the measures is based on the trust of the system participants only; \\
5) The anonymity of data of system & 5) & No country or authority guarantees the reliability of cryptocurrencies and does not \\
participants. & & recognize it as a universal settlement instrument; \\
& 6) & High probability of electronic hacking; \\
& 7) & Unreliable issuers of new cryptocurrencies. \\
\hline
\end{tabular}


The cryptocurrency system and market weaknesses include the non-material form (1). This means that, unlike ordinary currencies, cryptocurrencies cannot be physically seen or touched. The high volatility (2) of the course is a factor that can adversely affect the cryptocurrency market and instability. While many non-professional investors consider the rate volatility to be a good feature, it is possible to try to make a profit from these changes, but it only testifies to the unpredictability and volatility of the market. Weaknesses also include the absence of consumer protection errors (3). This means that you need to be careful when making transactions. It is not possible to return a transaction made after the incorrect data has been entered. Also, the value of the measures is often based only on the confidence of the system participants (4). It should be borne in mind that, as discussed above, the value of a cryptocurrency depends essentially on supply and demand, which is the result of the confidence expressed by market participants. Also, no country or institution guarantees that cryptocurrencies are completely reliable and they are not treated as global payment instruments (5), so often cryptocurrencies are linked to fraud and money laundering. Since cryptocurrencies are electronic currencies, there is a high likelihood of hacking into electronic media and stealing of funds (6). The last weakness is the unreliability of the creators of the new cryptocurrencies (7). The fact is that the creation of new cryptocurrencies is a very popular process, but often this process is unreasonable and only seeks to make money from the initial chips (ICO). According to Fisch (2019), the ICO is the initial issue of newly created cryptocurrency chips or coupons that people who have bought them in the future will be able to exchange for a product or service created with resources collected through ICO. Unfortunately, there has been a lot of scam over the last few years. Fraudsters advertise for organizing ICOs and develop a new product for the money they raise but disappear after stealing some of the funds. So, the public looks at the ICO more and more sceptically, and the central banks of the country, trying to manage the situation and the financial affairs, are starting to ban the initial chips.

Table 2 below lists the cryptocurrency systems and market opportunities and threats. The first option is the globalization of international trade (1). The second and last option is an increase in the volume of online shopping (2).

Table 2. Cryptocurrency systems and market SWOT analysis: opportunities and threats (composed by the authors)

\begin{tabular}{|c|c|}
\hline Opportunities $(\mathrm{O})$ : & Threats $(\mathrm{T})$ : \\
\hline 1) Globalization of international trade; & 1) Widespread use in the criminal world; \\
\hline 2) Increasing the volume of online shopping. & 2) Likelihood of a ban; \\
\hline & $\begin{array}{l}\text { 3) High probability of hacking into important system } \\
\text { nodes; }\end{array}$ \\
\hline & $\begin{array}{l}\text { 4) Increasing competition for other electronic payment in- } \\
\text { struments; }\end{array}$ \\
\hline & 5) Destruction of anonymity during operations. \\
\hline
\end{tabular}

Threats in Table 2 can be extensively used in the criminal world (1). A high proportion of users, especially those who do not change the cryptocurrencies into national currencies, can lead to the use of the market for illicit purposes, in particular for banned goods or terrorist financing. The lack of administrative control of the funds transferred also has a high probability that the market will be used for so-called money laundering. Recently, there have been frequent hearings of cryptocurrency bans (2). Governments in each country are beginning to raise questions about the regulation of cryptocurrencies, so the possibility that the market will be restricted in the future is not excluded. The following threat poses a high probability of hacking into important system nodes (3), which has recently become a major threat, and in fact, this situation is often repeated, thus stealing investors' funds. The latest threat is the growing competition for other electronic payment instruments (4). Nowadays, more and more electronic payment service providers are emerging, making it difficult to provide unique services that provide exclusivity and non-competitiveness. The destruction of anonymity in operations is identified as the last threat (5). Recently, companies that use a variety of stateof-the-art technology have helped break down operations on the blockchain. This means that operations can be traced and no longer be anonymous (chainalysis.com, $25^{\text {th }}$ February 2019).

\subsection{Analysis of cryptocurrencies capitalization and domination in the market}

Figure 2 below shows graphically the total market capitalization of the cryptocurrency since 2013, when the fever began, to this day $\left(28^{\text {th }}\right.$ January 2019$)$, by coingecko.com data.

The cryptocurrency capitalization determines the value of the cryptocurrencies. This means that it shows the size of investment volumes and is counted by the number of negotiable chips multiplied by their current price. The first major fluctuation was in May 2017, when on the $2^{\text {nd }}$ of May capitalization amounted to EUR 3560 million, on the $21^{\text {st }}$ of June to EUR 9416 million, and on the $3^{\text {rd }}$ of August capitalization amounted to EUR 14751 million. Such a big leap in capitalization was largely due to the sharp rise in bitcoin prices. At that time, the cryptocurrency market experienced the apogee, as the prices of many cryptocurrencies began to rise unexpectedly. The record peak time of cryptocurrency market capitalization was in December 2017 and in January 2018. This means that market capitalization has reached unexpected volumes on the $17^{\text {th }}$ of December in 2017; it reached EUR 50437 million and the largest market capitalization of cryptocurrency since its establishment was recorded on the $7^{\text {th }}$ of January in 2018 - it was 
EUR 68504 million (see Figure 2). This means that from May 2 until January 7 the market capitalization of cryptocurrencies increased almost twenty times $-1824.27 \%$ (see Table 3). After this day, the volume of the market capitalization began to decline and on April 4 it dropped to EUR 22139 million, although after reaching such amount, increased to EUR 36974 million on May 5. After May 5, the total capitalization of the market has declined and remained so until today as the capitalization of 3rd January 2019 amounted to only EUR 9843 million, which means that the capitalization since January 2018 decreased by $46.03 \%$ (see Table 3). The reason for this January 2018 crisis is the Chinese government's ban on trading digital currencies in China. China has blocked access to the country's currency exchange platforms, but also those whose headquarters are located abroad. The government's primary objective of such actions was to limit the number of cryptocurrency miners in the country in order to reduce electricity consumption (Bloomberg, 2018).

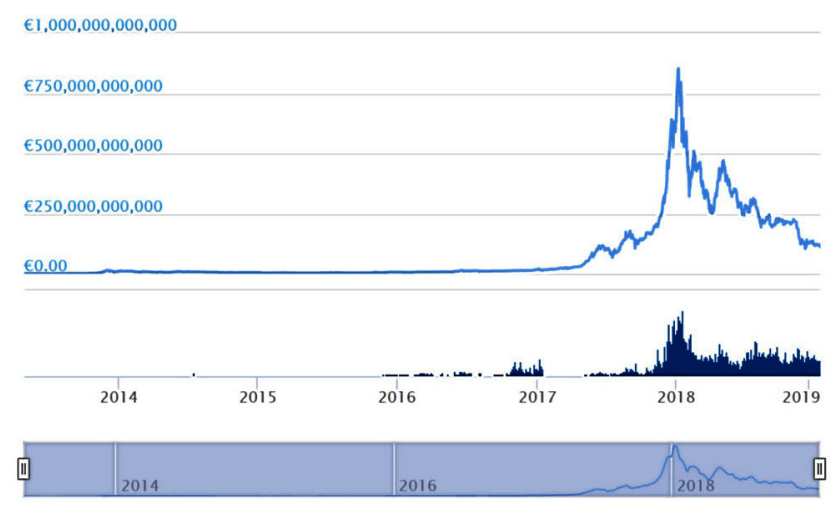

Figure 2. Total Capitalization of the cryptocurrency market in euro 2013-2019(coingecko.com, 2019)

Table 3. Percentage changes in cryptocurrency market capitalization on selected days (composed by the authors)

\begin{tabular}{|c|c|c|c|c|c|}
\hline 2017-05-02 & 2018-01-07 & $\begin{array}{c}\text { Change from 2017-05-02 } \\
\text { until 2018-01-07 }\end{array}$ & 2018-01-07 & 2019-01-31 & $\begin{array}{c}\text { Change from 2018-01-07 } \\
\text { until 2019-01-31 }\end{array}$ \\
\hline $\begin{array}{c}\text { EUR 3 560 } \\
\text { million }\end{array}$ & $\begin{array}{c}\text { EUR 68 504 } \\
\text { million }\end{array}$ & $1824.27 \%$ & $\begin{array}{c}\text { EUR 68 504 } \\
\text { million }\end{array}$ & $\begin{array}{c}\text { EUR 36 974 } \\
\text { million }\end{array}$ & $-46.03 \%$ \\
\hline
\end{tabular}

The steady decline in cryptocurrency capitalization creates a pessimistic atmosphere for participants and economists of cryptocurrencies. N. Roubini (2018) stated that "Cryptocurrencies will soon experience an apocalypse" (31 January 2019). Although the University of London scientist P. Tasca (2018) in November of the same year expressed an opposite view. He assured that the "cryptocurrency market is becoming more mature" and predicted greater stability, security and liquidity (31 January 2019).

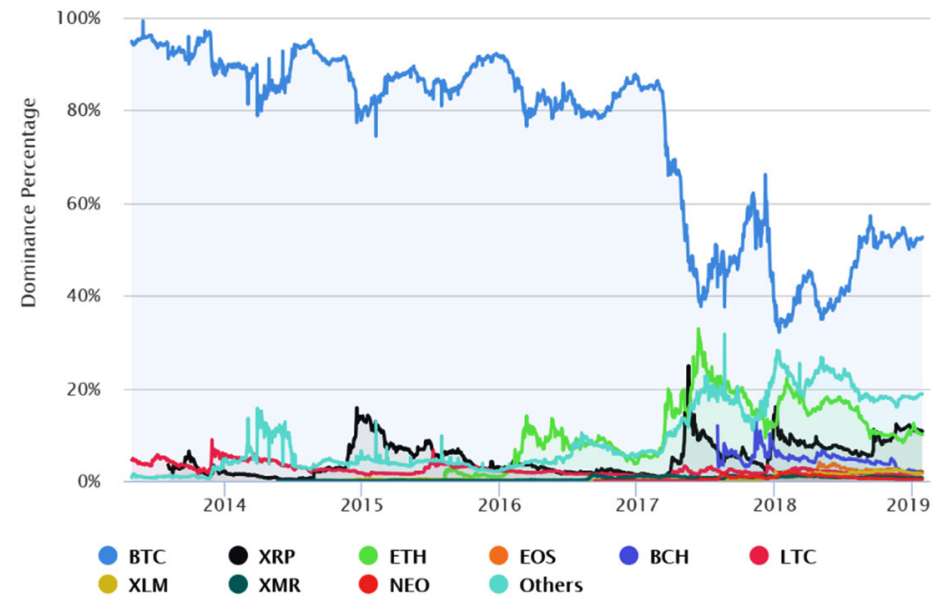

Figure 3. Percentage dominance of the most popular cryptocurrencies in the market in 2013-2019 (coingecko.com, 2019)

Figure 3 shows the market dominance of the most popular cryptocurrencies in the period of 2013-2019. It appears that in the entire market of cryptocurrencies in the analysed period the most popular is bitcoin. By the end of February 2017, it occupied more than $80 \%$ of the total market, but in March 2017, the volumes of other cryptocurrencies, such as ETH, XRP etc., began to increase dramatically and BTC's dominance began to decline strongly and fell to $37.56 \%$ on 19 June 2017, while ETH reached a record high of $29.31 \%$, while XRP increased to $9.71 \%$. This was caused by a 
sharp increase in the price of ETH and a fast increase in popularity. At that time, there was much hope in ETH, many economists and financiers believed in the success of it, but this virtual currency did not reach higher levels of dominance than XRP. By today, BTC remains the most popular and dominant cryptocurrency, which on 31 January 2019 accounts for $52.45 \%$ of the total cryptocurrency market.

\section{Analysis and forecast of household investment in cryptocurrencies}

The scope of the cryptocurrency exchange X clients' monthly investment in cryptocurrencies during the period of 2016-2019 is further analysed. Figure 4 depicts the change in household investment in BTC, DASH, ETH and NEM, while Appendix 1 shows the change of investment in the cryptocurrency exchange $\mathrm{X}$ data and the percentage change of investment for each month.

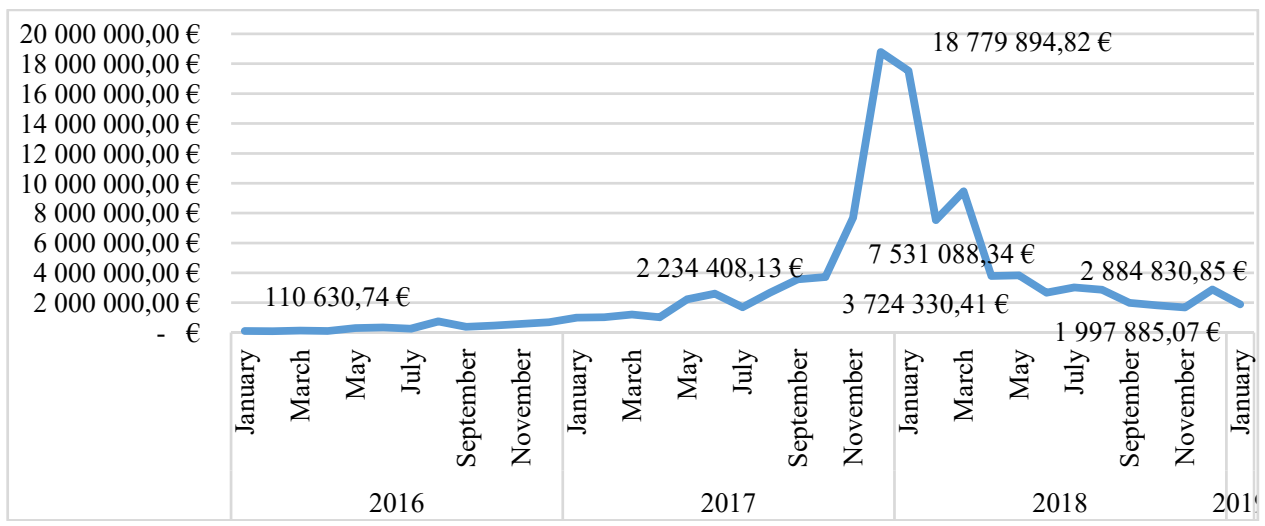

Figure 4. Change of household investment in BTC, DASH, ETH and NEM in the period of 2016-2019 (compiled by the authors according to the data of exchange $\mathrm{X}$ )

At the end of 2017 and early 2018, there is a very high level of active investors in the cryptocurrency and an increase in the volume of cryptocurrency purchases. According to the data of the exchange X, in January 2016, a total of EUR 110630.74 was spent to buy cryptocurrencies. The first more rapid growth was observed in 2016 when in August, cryptocurrencies were bought for EUR 745 719.18, which meant an increase of $189.56 \%$ of the volume of investments in the cryptocurrencies in exchange X compared to July. In 2017, there were record-breaking investments in the volume of cryptocurrencies. EUR 1 million investment went beyond January 2017, when the chain percentage change compared to the previous month was $45.99 \%$, while the investment in the cryptocurrencies in the exchange X amounted to EUR 1004 314.53. In May of the same year, the volume of household investment in cryptocurrencies exceeded the threshold of 2 million and amounted to EUR 2334 408.13. The peak of household investment in cryptocurrencies was in September 2017, when investment volumes exceeded EUR 3 million. In November, with a chain percentage change of $105.80 \%$, cryptocurrencies were bought for EUR 7664647.98 at the exchange X. December 2017 is an absolute record for investing in cryptocurrencies, as at that time, in the exchange, households purchased cryptocurrencies two and a half times more than last November and reached a peak of EUR 18779 894.82. In 2018, investment volumes were on a downward trend, reaching only EUR 1889673.83 in January 2019.

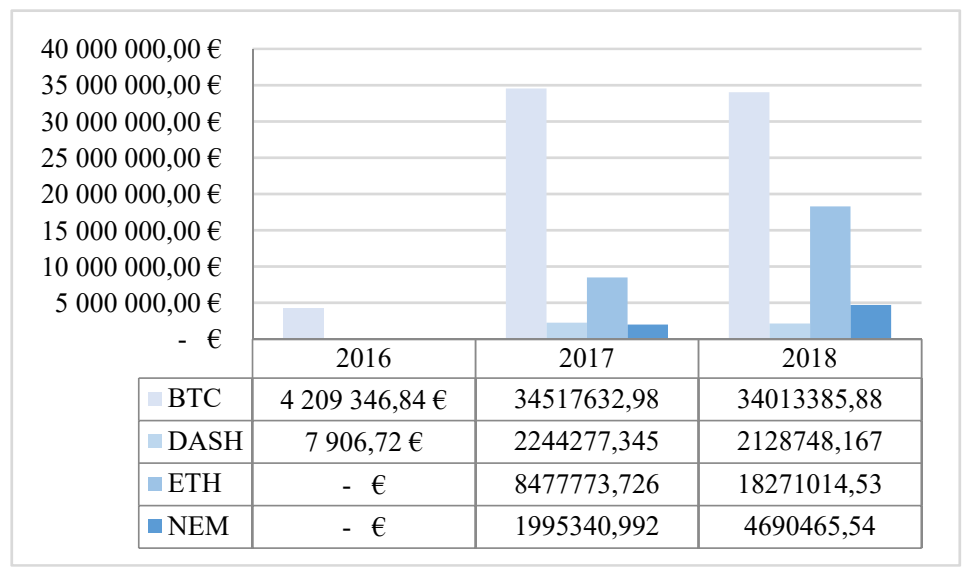

Figure 5. Structure of household investments in cryptocurrencies in the period of 2016-2018 (compiled by the authors according to the data of exchange $\mathrm{X}$ ) 
In 2016-2018, in the exchange $X$ there were mostly unambiguously investments in bitcoins (see Figure 5). In 2016 - in BTC and DASH at EUR 4209346.84 and EUR 7906.72 respectively. In 2017, the exchange X added an additional two alternatives - ETH and NEM, which amounted to EUR 8477773.73 and EUR 1995340.99 respectively. In 2017, the biggest investment was in BTC - even EUR 34517632.98 Eur. In 2018, X's investment in BTC fell slightly, reaching EUR 34013 385.88, but the investment in ETH increased strongly, which in 2018 in the exchange, amounted to EUR 18271014.53 .

\subsection{Forecast of household investment in cryptocurrencies}

The stormy years of 2017 and 2018 in the cryptocurrency market have caused great confusion. The rapidly growing popularity of cryptocurrencies in December 2017, created an optimistic mood about the success of the cryptocurrency market. However, nowadays trends show that the cryptocurrency market can be just another bubble bursting with negative consequences for all households investing in them. A lot of discussion among scientists these days raises the question of whether the market has the potential to expand and develop, or does it still have its own loopholes?

Table 4. ARIMA $(2,1,0)$ model (Gaussian distribution) (composed by the authors)

\begin{tabular}{|c|c|c|c|}
\hline Parameter & Value & Error & Standard t Statistic \\
\hline Constant & 56252.9 & 623737 & 0.0901869 \\
\hline $\mathrm{AR}\{1\}$ & 0.0450533 & 0.206023 & 0.21868 \\
\hline $\mathrm{AR}\{2\}$ & -0.182273 & 0.0774069 & -2.35474 \\
\hline Variance & $8.36884 \mathrm{e}+12$ & 0.100503 & $8.32693 \mathrm{e}+13$ \\
\hline
\end{tabular}

The answer to this question will be the forecast of households' investment in cryptocurrencies for one year ahead according to the ARIMA $(2,1,0)$ forecast model. This model has one degree of nonseasonal differencing and two AR lags. By default, the innovation distribution is Gaussian with a constant variance (see Table 4). Just one AR coefficient is acceptable. Figure 6 shows that the residuals are reasonably normally distributed and uncorrelated.
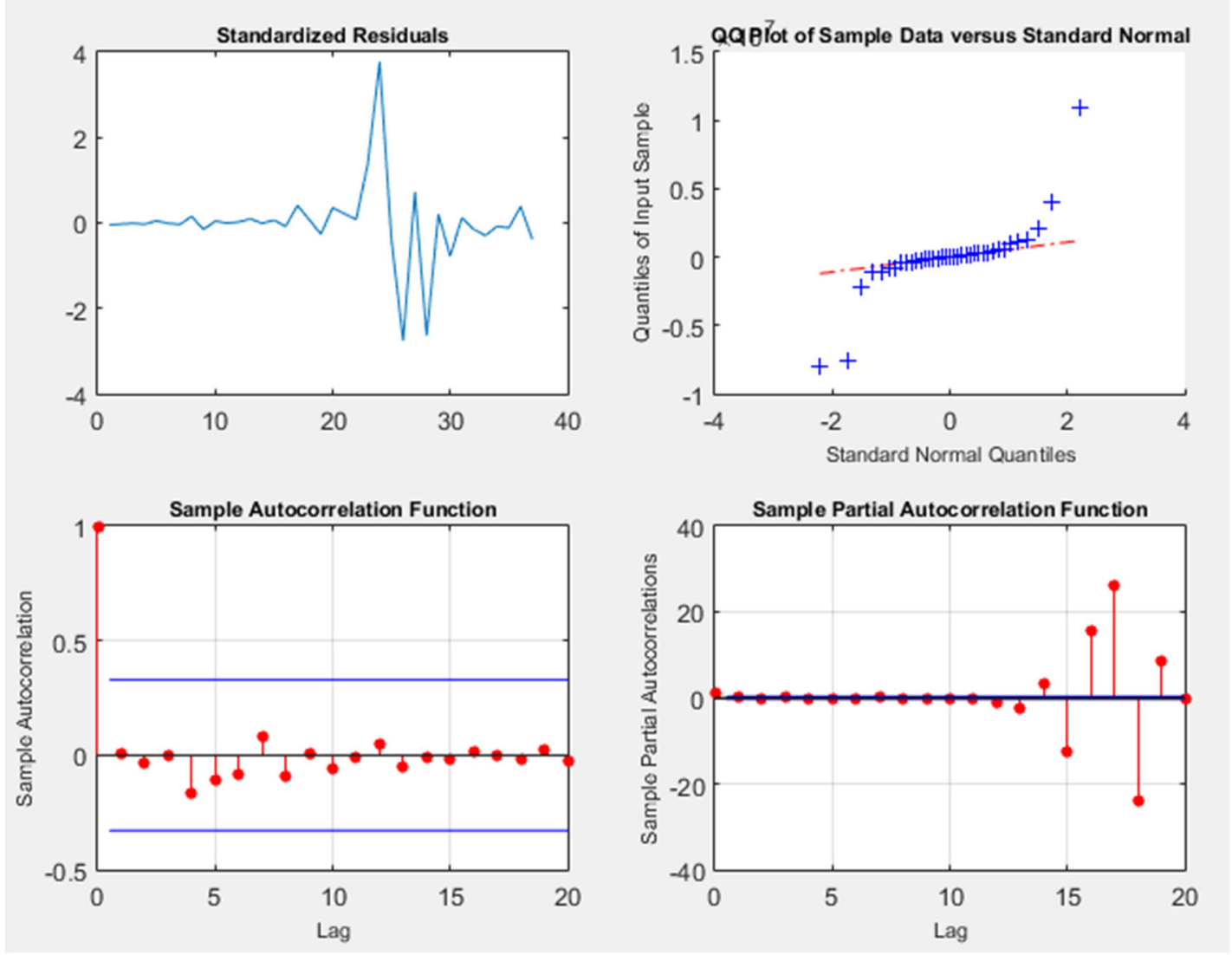

Figure 6. Distribution and correlation of the residuals (compiled by the authors according to the data of exchange $\mathrm{X}$ ) 


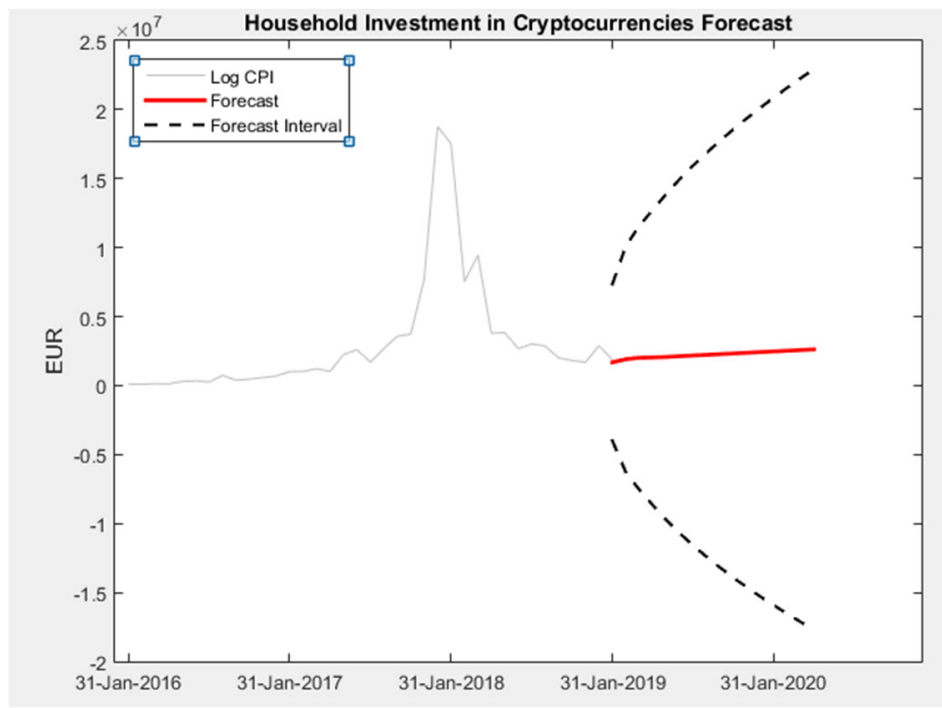

Figure 7. Forecast of household investment in cryptocurrencies for a year ahead (compiled by the authors according to the data of exchange $\mathrm{X}$ )

The forecast for household investment (see Figure 7) in the cryptocurrencies for a year has revealed that the volume of investment in the chosen cryptocurrencies is likely to maintain upward trends. Prediction results promise optimistic values of the market, which means that the volume of investment in cryptocurrencies in the future is likely to grow. Calculated data suggest that from February 2019, household investment in cryptocurrencies will gain an upward trend that will last until January 2020.

\section{Conclusions}

The increased demand for new financial technologies in the last decade has led to the emergence of cryptocurrencies and its popularity is steadily growing. The cryptocurrency market is still a young market that emerged in 2009 but has only become popular in 2013, although there is a high demand for new scientific investigations. The majority of scientists agree that the main reason for the emergence of ever-new cryptocurrencies is to create alternative, decentralized, independent and relatively anonymous money and payment systems.

Cryptocurrencies are not just a payment system. Nowadays, it is a very popular investment tool that allows you to earn income from sudden and hard-to-predict changes in cryptocurrency prices. This is a very risky market because the changes in the value of the cryptocurrency take place almost every minute, are sudden, difficult to predict and very significant.

The top 10 cryptocurrencies currently are Bitcoin, Ethereum, XRP, Bitcoin Cash, Stellar, EOS, Litecoin, Cardano, Monero and Tether. The unmatched frontrunners in this hierarchy are bitcoins (BTCs) with a market share of as much as $52.25 \%$ of total market capitalization.

After analyzing the market capitalization of cryptocurrencies, it was found that the largest capitalization was at the end of 2017 and at the beginning of 2018 when the prices of cryptocurrencies rose record-breaking. This rise in prices has been caused by many political and economic factors, such as the statements of politicians from influential countries and the interest of the media in the cryptocurrencies and their market.

The analysis of household investment in the cryptocurrencies by exchange's X data reveals that the higher the price of cryptocurrencies is, the greater interest and more money invested in the cryptocurrencies can be.

The results of households' investment in cryptocurrencies forecast show that investment volumes are likely to continue to grow in the near future. On this basis, it can be said that the cryptocurrency market has the potential to expand and develop further on.

\section{Acknowledgements}

The authors of the article would like to thank Assoc Prof Dr Nijole Maknickiene who contributed to the work on forecasting model. The insights from the researcher were very useful.

\section{References}

Andrianto, Y., \& Diputra, Y. (2017). The effect of cryptocurrency on investment portfolio effectiveness. Journal of Finance and Accounting, 5(6), 229-238. https://doi.org/10.11648/j.jfa.20170506.14 
Pieczulis, I.; Taujanskaite, K. 2019. Analysis of cryptocurrencies market: current situation, tendencies of household investment and future forecasting

Andrychowicz, M., Dziembowski, S., Malinowski, D., \& Mazurek, Ł. (2016). Secure multiparty computations on Bitcoin. Communications of the ACM, 59(4), 76-84. https://doi.org/10.1145/2896386

Antonakakis, N., Chatziantoniou, I., \& Gabauer, D. (2019). Cryptocurrency market contagion: Market uncertainty, market complexity, and dynamic portfolios. Journal of International Financial Markets, Institutions and Money (in press). https://doi.org/10.1016/j.intfin.2019.02.003

Barber, S., Boyen, X., Shi, E., \& Uzun, E. (2012). Bitter to better - how to make Bitcoin a better currency. In A. D. Keromytis (Ed.), Financial cryptography and data security (pp. 399-414). Berlin, Heidelberg: Springer. https://doi.org/10.1007/978-3-642-32946-3_29

Bentov, I., \& Kumaresan, R. (2014). How to use Bitcoin to design fair protocols. In Advances in cryptology - CRYPTO 2014 (pp. 421-439). Berlin, Heidelberg: Springer. https://doi.org/10.1007/978-3-662-44381-1_24

Bloomberg. (2018). China escalates crackdown on cryptocurrency trading. Retrieved from https://www.bloomberg.com

Bonneau, J., Miller, A., Clark, J., Narayanan, A., Kroll, J. A., \& Felten, E. W. (2015). SoK: research perspectives and challenges for Bitcoin and cryptocurrencies. In IEEE Symposium on Security and Privacy, 17-21 May 2015, San Jose, CA, USA. IEEE. https://doi.org/10.1109/SP.2015.14

Borri, N. (2019). Conditional tail-risk in cryptocurrency markets. Journal of Empirical Finance, 50, 1-19. https://doi.org/10.1016/j.jempfin.2018.11.002

Camenisch, J., Hohenberger, S., \& Lysyanskaya, A. (2005). Compact E-cash. In R. Cramer (Ed.), Advances in cryptology EUROCRYPT 2005 (pp. 302-321). Berlin, Heidelberg: Springer. https://doi.org/10.1007/11426639_18

Caporale, G. M., \& Zekokh, T. (2019). Modelling volatility of cryptocurrencies using Markov-Switching GARCH models. Research in International Business and Finance, 48, 143-155. https://doi.org/10.1016/j.ribaf.2018.12.009

Caporale, G. M., Gil-Alana, L., \& Plastun, A. (2018). Persistence in the cryptocurrency market. Research in International Business and Finance, 46, 141-148. https://doi.org/10.1016/j.ribaf.2018.01.002

Chaim, P., \& Laurini, M. P. (2018). Volatility and return jumps in Bitcoin. Economics Letters, 173, 158-163. https://doi.org/10.1016/j.econlet.2018.10.011

Chainalysis.com. (2019, February 25). Cryptocurrency payments reporting system. Retrieved from https://www.chainalysis.com/

Chan, S., Chu, J., Nadrajah, S., \& Osterrieder, J. (2017). A statistical analysis of cryptocurrencies. Journal of Risk and Financial Management, 10, 1-23. https://doi.org/10.3390/jrfm10020012

Chaum, D., Fiat, A., \& Naor, M. (1990). Untraceable electronic cash. In S. Goldwasser (Ed.), Advances in cryptology - CRYPTO' 88 (pp. 319-327). New York: Springer. https://doi.org/10.1007/0-387-34799-2_25

Ciaian, P., Rajcaniova, M., \& Kancs, A. (2016). The economic of BitCoin price formation. Applied Economics, 48(19), $1799-1815$. https://doi.org/10.1080/00036846.2015.1109038

Coingecko.com. (2019, Januray 28). Cryptocurrency market ratings. Retrieved from https://www.coingecko.com/en

CoinMarketCap.com. (2018, November 13). Research, statistics and capitalization of the cryptocurrency market. Retrieved from https://coinmarketcap.com

Corbet, S., Larkin, C. J., Lucey, B. M., \& Yarovaya, L. (2018). Kodakcoin: A blockchain revolution or exploiting a potential cryptocurrency bubble? https://doi.org/10.2139/ssrn.3140551

Corbet, S., Lucey, B., \& Yarovaya, L. (2017). Datestamping the Bitcoin and Ethereum bubbles. Journal of Finance Research Letters, 26, 81-88. https://doi.org/10.1016/j.frl.2017.12.006

Cryptocurrencies will soon experience apocalypse in Roubini opinion. (2018). Retrieved from https://www.lrytas.lt/verslas/rinkospulsas/2018/10/24/news/krize-ispranasaves-garsus-ekonomistas-n-roubini-kriptovaliutos-tuoj-patirs-apokalipse--8003446/

Dibrova, A. (2016). Virtual currency: new step in monetary development. Procedia - Social and Behavioral Sciences, $229,42-49$. https://doi.org/10.1016/j.sbspro.2016.07.112

Dourado, E., \& Brito, J. (2014). The new Palgrave Dictionary of Economics: cryptocurrency. Retrieved from https://coincenter.org/wp-content/uploads/2015/05/cryptocurrency-article.pdf.

Dwyer, G. P. (2015). The economics of Bitcoin and similar private digital currencies. Journal of Financial Stability, 17(C), 81-91. https://doi.org/10.1016/j.jfs.2014.11.006

Eom, C., Kaizoji, T., Kang, S. H., \& Pichl, L. (2019). Bitcoin and investor sentiment: Statistical characteristics and predictability. Physica A: Statistical Mechanics and its Applications, 514, 511-521. https://doi.org/10.1016/j.physa.2018.09.063

Fisch, C. (2019). Initial coin offerings (ICOs) to finance new ventures. Journal of Business Venturing, 34(1), 1-22. https://doi.org/10.1016/j.jbusvent.2018.09.007

Fry, J., \& Cheah, E. T. (2015). Speculative bubbles in Bitcoin markets? An empirical investigation into the fundamental value of Bitcoin. Journal of Economics Letters, 130, 32-36. https://doi.org/10.1016/j.econlet.2015.02.029

Fry, J., \& Cheah, E. T. (2016). Negative bubbles and shocks in cryptocurrency markets. International Review of Financial Analysis, 47, 343-352. https://doi.org/10.1016/j.irfa.2016.02.008

Geiregat, S. (2018). Cryptocurrencies are (smart) contracts. Computer Law \& Security Review, 34, 1144-1149. https://doi.org/10.1016/j.clsr.2018.05.030

Glaser, F., Zimmermann, K., Haferkorn, M. W. M., \& Siering, M. (2014). Bitcoin-asset or currency? Revealing users' hidden intentions. Paper presented at the 22nd European Conference on Information Systems (ECIS), Tel Aviv, Israel.

Hafner, C. (2018). Testing for bubbles in cryptocurrencies with time-varying volatility. https://doi.org/10.2139/ssrn.3105251

Hayes, A. S. (2016). Cryptocurrency value formation: an empirical analysis leading to a cost of production model for valuing Bitcoin. Telematics and Informatics (in press). https://doi.org/10.2139/ssrn.2648366 
Halaburda, H., \& Gandal, N. (2018). Competition in the cryptocurrency market (Working Paper No. 14-17). NET Institute. https://doi.org/10.2139/ssrn.2506463

Hileman, G., \& Rauchs, M. (2017). Global cryptocurrency benchmarking study. University of Cambridge, Judge Business School: Cambridge Centre for Alternative Finance. Retrieved from https://www.jbs.cam.ac.uk/fileadmin/user_upload/ research/centres/alternative-finance/downloads/2017-global-cryptocurrency-benchmarking-study.pdf

How the cryptocurrency market will look like in 2019 in P. Tasca opinion. (2018). Retrieved from https://www.delfi.lt/ verslas/verslas/eksperto-prognoze-kaip-kriptovaliutu-rinka-atrodys-2019-metais.d?id=79546153

Yermack, D. (2013). Is Bitcoin a real currency? An economic appraisal. In The handbook of digital currency (pp. 31-44). https://doi.org/10.3386/w19747

Yi, S., Xu, Z., \& Wang, G. J. (2018). Volatility connectedness in the cryptocurrency market: Is Bitcoin a dominant cryptocurrency? International Review of Financial Analysis, 60, 98-114. https://doi.org/10.1016/j.irfa.2018.08.012

Kądziołka, K. (2015). Ocena ryzyka inwestycji w kryptowalutę Bitcoin. Contemporary Economy Electronic Scientific Journal, 6(3), $1-8$.

Kajtazi, A., \& Moro, A. (2018). The role of bitcoin in well diversified portfolios: A comparative global study. International Review of Financial Analysis (in press).

Katsiampa, P. (2017). Volatility estimation for Bitcoin: A comparison of GARCH models. Journal of Economics Letters, 158(C), 3-6. https://doi.org/10.1016/j.econlet.2017.06.023

Kosba, A., Miller, A., Papamanthou, C., Shi, E., \& Wen, Z. (2015). Hawk: the blockchain model of cryptography and privacypreserving smart contracts. Retrieved from https://eprint.iacr.org/2015/675.pdf

Nakamoto, S. (2008). Bitcoin: a peer-to-peer electronic cash system. Retrieved from: https://bitcoin.org/bitcoin.pdf

Narayanan, A., Bonneau, J., Felten, E., \& Miller, A. (2016). Bitcoin and cryptocurrency technologies: A comprehensive introduction. Princeton University Press.

Phillip, A., Chan, J. S. K., \& Peiris, S. (2018). A new look at cryptocurrencies. Journal of Economics Letters, 163, 6-9. https://doi.org/10.1016/j.econlet.2017.11.020

Platanakis, E., \& Urquhart, A. (2018). Should investors include Bitcoin in their portfolios? A Portfolio theory approach. https://doi.org/10.2139/ssrn.3215321

Platanakis, E., \& Urquhart, A. (2019). Portfolio managements with cryptocurrencies: The role of estimation risk. Economics Letters, 177, 76-80. https://doi.org/10.1016/j.econlet.2019.01.019

Rosenberg, B. (2010). Handbook of financial cryptography and security (1st ed.). New York: Chapman and Hall/CRC. https://doi.org/10.1201/9781420059823

Ruffing, T., Kate, A., \& Schröder, D. (2015). Liar, liar, coins on fire!: Penalizing equivocation by loss of Bitcoins. In CCS '15 Proceedings of the 22nd ACM SIGSAC Conference on Computer and Communications Security, Denver, Colorado, USA, 1216 October (pp. 219-230). New York, USA. https://doi.org/10.1145/2810103.2813686

Schoenmakers, B. (1998). Security aspects of the Ecash ${ }^{\mathrm{TM}}$ payment system. In State of the art in applied cryptography (pp. 338352). Berlin, Heidelberg: Springer. https://doi.org/10.1007/3-540-49248-8_16

Sompolinsky, Y., \& Zohar, A. (2013). Accelerating Bitcoin's transaction processing fast money grows on trees, not chains. Retrieved from https://pdfs.semanticscholar.org/4016/80ef12c04c247c50737b9114c169c660aab9.pdf

Wang, L., Shen, X., Li, J., Shao, J., \& Yang, Y. (2019). Cryptographic primitives in blockchains. Journal of Network and Computer Applications, 127, 43-58. https://doi.org/10.1016/j.jnca.2018.11.003 
Pieczulis, I.; Taujanskaitè, K. 2019. Analysis of cryptocurrencies market: current situation, tendencies of household investment and future forecasting

\section{Appendix 1}

Percentage change of household investment in cryptocurrencies in 2016-2019 by exchange X data (compiled by the authors)

\begin{tabular}{|c|c|c|c|c|c|c|}
\hline Month & Year & $\begin{array}{c}\text { Investments in } \\
\text { cryptocurrencies }\end{array}$ & Percentage change & Year & $\begin{array}{l}\text { Investments in } \\
\text { cryptocurrencies }\end{array}$ & $\begin{array}{c}\text { Percentage } \\
\text { change }\end{array}$ \\
\hline January & \multirow{12}{*}{2016} & $110630.74 €$ & - & \multirow{12}{*}{2018} & $17534865.35 €$ & -6.63 \\
\hline February & & $93064.11 €$ & -15.88 & & $7531088.34 €$ & -57.05 \\
\hline March & & $138170.97 €$ & 48.47 & & $9457607.98 €$ & 25.58 \\
\hline April & & $114703.84 €$ & -16.98 & & $3790687.77 €$ & -59.92 \\
\hline May & & $298248.88 €$ & 160.02 & & $3836513.60 €$ & 1.21 \\
\hline June & & $339118.22 €$ & 13.70 & & $2676919.46 €$ & -30.23 \\
\hline July & & $257534.95 €$ & -24.06 & & $3020398.46 €$ & 12.83 \\
\hline August & & $745719.18 €$ & 189.56 & & $2870421.82 €$ & -4.97 \\
\hline September & & $388869.07 €$ & -47.85 & & $1997885.07 €$ & -30.40 \\
\hline October & & $465680.18 €$ & 19.75 & & $1818809.68 €$ & -8.96 \\
\hline November & & $577597.91 €$ & 24.03 & & $1683585.72 €$ & -7.43 \\
\hline December & & $687915.51 €$ & 19.10 & & $2884830.85 €$ & 71.35 \\
\hline January & \multirow{12}{*}{2017} & $1004314.53 €$ & 45.99 & 2019 & $1889673.83 €$ & -34.50 \\
\hline February & & $1024854.37 €$ & 2.05 & & & \\
\hline March & & $1214573.02 €$ & 18.51 & & & \\
\hline April & & $1031336.19 €$ & -15.09 & & & \\
\hline May & & $2234408.13 €$ & 116.65 & & & \\
\hline June & & $2606477.08 €$ & 16.65 & & & \\
\hline July & & $1695746.89 €$ & -34.94 & & & \\
\hline August & & $2681791.51 €$ & 58.15 & & & \\
\hline September & & $3572650.11 €$ & 33.22 & & & \\
\hline October & & $3724330.41 €$ & 4.25 & & & \\
\hline November & & $7664647.98 €$ & 105.80 & & & \\
\hline December & & $18779894.82 €$ & 145.02 & & & \\
\hline
\end{tabular}

